EPiC Series in Language and Linguistics
Volume 3, 2018, Pages 65-71
LSP in Multi-disciplinary contexts of
Teaching and Research. Papers from the
16th International AELFE Conference

\title{
Terminología y traducción en contextos especializados (alemán-español): el sector vitivinícola
}

\author{
María del Carmen Balbuena Torezano ${ }^{\mathrm{a}}$ \\ ${ }^{a}$ Universidad de Córdoba, Avda. Medina Azahara 5, Córdoba 14017, España
}

\begin{abstract}
Es una realidad aceptada de forma unánime que el traductor especializado ha de conocer el campo temático en el que trabaja, siendo por tanto imprescindible que junto a la competencia lingüística sea necesario además un profundo conocimiento de la temática sobre la cual versa el texto al que se ha de enfrentar. El presente trabajo aborda las principales características de una terminología propia de un sector, el de la vitivinicultura, que contiene numerosas unidades de significado especializadas, dada la ingente cantidad de dominios y subdominios léxicos que subyacen al evento [vino]. Partimos de las premisas establecidas para la ejecución del proyecto WeinApp: Sistema multilingüe de información y recursos vitivinícolas, centrado especialmente en el estudio del léxico desde perspectivas contrastivas y la búsqueda de equivalencias para la correcta traducción de los textos especializados. No en vano, dentro del sector agroalimentario, la vitivinicultura constituye un amplio campo de estudio no sólo dentro de las denominadas disciplinas científicas, sino también, dentro del campo de las Humanidades, en torno a tipologías textuales, fraseología, léxico especializado, culturemas y análisis contrastivo aplicado a la traducción de textos y a la interpretación de discursos, dada la indudable relevancia del producto en torno al cual surgen todas estas unidades lingüísticas, textuales y culturales. El conocimiento de las estructuras gramaticales, la formación de palabras y los mecanismos para la creación de nuevos términos en lengua original -el alemán-, posibilitará, como veremos a lo largo de la exposición del trabajo, una herramienta útil de trabajo para el traductor, que logrará con éxito la correcta traducción de los textos al español.
\end{abstract}

Keywords: Terminología; vitivinicultura; ontología; traducción especializada.

\begin{abstract}
It is a well-known truth translators of specialized texts must know the field they work on. Thus, It is necessary for them to have a linguistic competence, in addition to a broad knowledge of the text theme they face. The present work focuses on the main charateristics of the wine sector terminology, which contains many specialized meaning units, given the vast amount of lexical domains and subdomains underlying the lexical field [wine]. The starting point is the premises established by the project WeinApp: Sistema multilingüe de información y recursos vitivinicolas, focused on the study of the lexicon from a constrastive perspective and the search for equivalences in order to translate specialized texts correctly. For these
\end{abstract}


purposes, within the agrifood sector, viticulture is a large field of study not only within the scientific disciplines, but also within Humanities regarding text typologies, phraseology, specialized lexicon, culturemes and contrastive analysis applied to translation of texts and the interpretation of discourses, owing to the undeniable relevance of the product from which arise all these linguistic, cultural and textual units. The knowledge of grammar structures, word formation processes and new term formation mechanisms in the source language -the German language- may provide, as it is proved throughout the presentation, a useful tool for translators, who will find the right translation for the texts into Spanish

Keywords: Terminology; vitiviniculture, ontology, specialized trasnslation.

\section{El léxico de la vitivinicultura}

El lenguaje del vino (en alemán: Weinsprache) combina la lengua general y el lenguaje especializado; a ello cabe añadir el uso de términos propios de la jerga, muy distintos en función de las distintas zonas vitivinícolas, lo que dificulta la comprensión de quien no es especialista en la materia. Así, por ejemplo, es posible hablar de "filtrado" o "filtración", de "pisa" o de "pisado", de "volteo" o de "vuelta", dependiendo de la zona geográfica productora de vino. El presente trabajo aborda parte de los estudios del proyecto Weinapp: Sistema multilingüe de información y recursos vitivinicolas ${ }^{I}$, centrado fundamentalmente en el estudio del léxico desde perspectivas contrastivas. En efecto, es posible encontrar textos fundamentalmente dirigidos al consumidor; la función de dichos textos es en su mayor parte publicitaria, y se centran en la descripción del vino como producto, persiguiendo con ello su consumo. Se trata, pues, de textos no muy alejados del lenguaje general, como lo demuestra el uso de términos como Alkoholgehalt ("graduación alcohólica", literalmente: "contenido en alcohol"), Geschmacksrichtung ("tipo según el sabor", literalmente: "dirección del sabor o del gusto") o Lagerfähigkeit ("caducidad", "consumir preferentemente antes de", literalmente: "almacenable hasta").

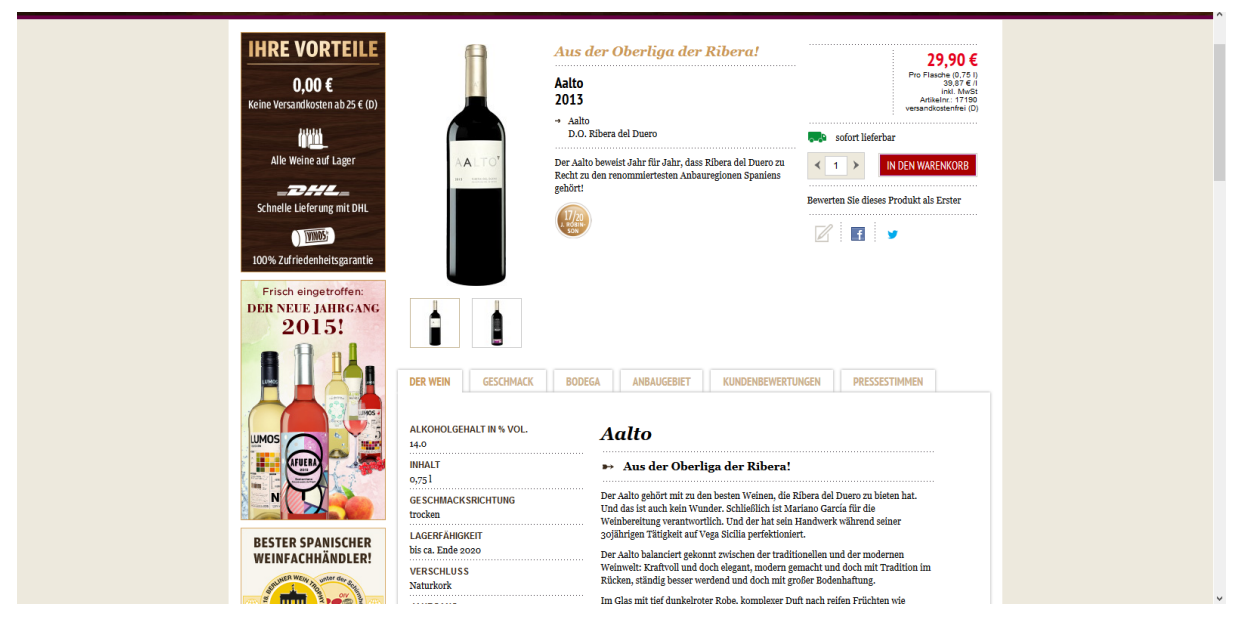

Fig. 1. Texto publicitario para el consume de vino. Fuente: http://www.regio-weinkaufen.de

\footnotetext{
${ }^{1}$ Ref. FFI 2016-79785-R, Ministerio de Economía y Competitividad.
} 
Otros textos, por el contrario, están dirigidos a especialistas, y por ello no es infrecuente encontrar términos especializados, como "hidroeyector", "geomembrana", "percolado" o "anaerobiosis", entre otros, incluidos en la figura 2. En efecto, se trata de un texto que describe un determinado sistema para evacuar los restos de líquidos y olores de la bodega, dirigido, por tanto, a enólogos e ingenieros especializados en el sector:

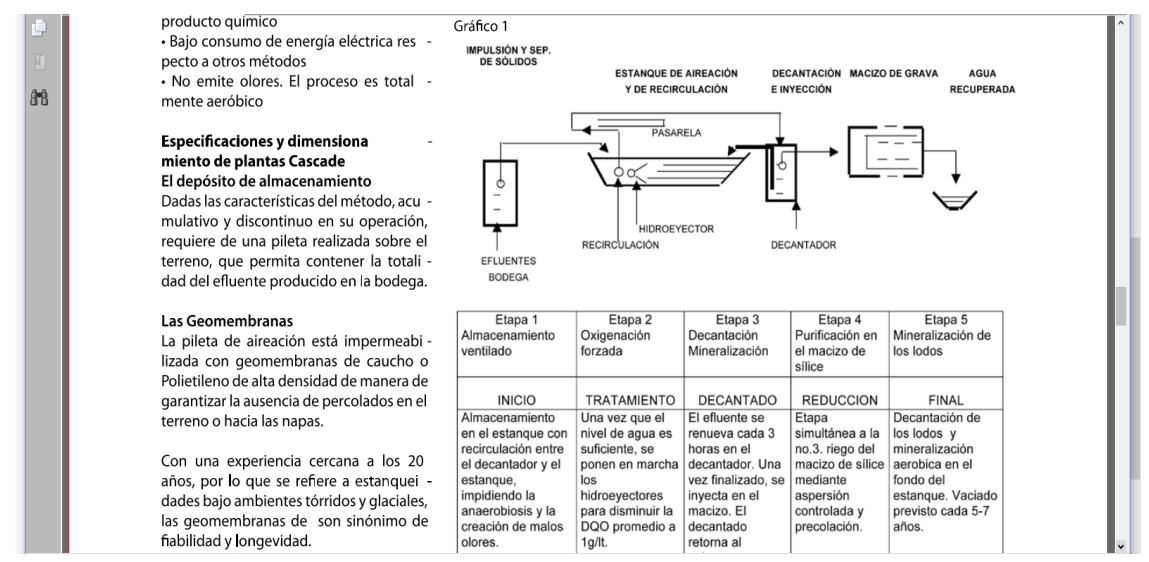

Fig. 2. Tratamiento de efluentes vitivinícolas. Método Cascade. http://www.consejodeenologos.com.ar

\section{Dominios y subdominios léxicos de la vitivinicultura (alemán-español)}

La dificultad que presenta la traducción de textos vitivinícolas -especialmente en el nivel léxico-semántico - queda patente en la ingente cantidad de dominios y subdominos léxicos presentes en este ámbito. Así, por ejemplo, dentro del dominio [vid / Rebe], es posible determinar otros muchos subdominios, tales como [taxonomía/ Taxonomie], [fenología/ Phänologie], [morfología/ Morphologie], [poda / Schnitt], [patología vitícola /Rebkrankheiten] o [vendimia/ Weinlese]. Éstos, a su vez, se dividen en numerosos subdominios. Así, por ejemplo, dentro del subdominio [taxonomía/ Taxonomie] podemos encontrar los subdominios [especies de vid/ Rebsorten] y [tipos de uva/ Traubensorten]; dentro del subsudominio [fenología/ Phänologie] encontramos los subdominios [parada vegetativa/Winterruhe], [hinchado de yemas/Beginn des Knospenschwellen], [yemas verdes/ Grünpunktstadium], [apertura de yemas/ Austrieb der Blätter], [hojas expandidas/ Blätter entfaltet], [influorescencias visibles/ sichtbare Gescheine], [influorescencias separadas/ Vergrösserung der Gescheine], [botones florales/ Einzelblüten], [floración/ Blühen], [baya/ Beere], [baya guisante/ erbsengrosse Beere], [compactación del racimo/ Traubenschluss], [envero/ Farbumschlag], [maduración/ Fruchtreife] y [agostamiento/ Blattfall]; pertenecientes al subdominio [morfología/ Morphologie] son los subdominios [sistema radical/ Wurzelsystem], [tronco/Stamm], [ramas/Ästen], [pámpanos/Weinranke], [hojas/ Blätter], [yemas/Knospen], [zarcillos/Ranken], [racimos/ Trauben], [flor/Blüte] y [fruto/ Frucht]; dentro del subdominio [poda/ Rebschnitt] encontramos otros como [poda en seco/ Winterschnitt] - y, a su vez, dentro de éste los subdominios [cortes/ Schnitt], [sistema de poda/ Schnittsystem] y [emparrados/Laubwand] - y [poda en verde/ Sommerschnitt] —y, a su vez, dentro de este otros como [despampanado/ Weinblätter Entfernung], [emparrado/ Laubwand], [despunte/ KnospenEntfernung], [aclareo/ Grünschnitt] y [deshojado/ Entblätterung]—; por su parte, el subdominio 
[patología vitícola/ Rebkrankungen] contiene los subdominios [hongos/ Pilzen], [bacterias/ Bakterien], [virus/ Viren], [micoplasmas/ Mykoplasmen], [insectos/ Insekten], [nematodos/ Nematoden], [ácaros/Milben], [moluscos/Mollusken], [vertebrados/Vertebrate], y [tratamientos fitosanitarios/ Pflanzenschutzbehandlung]; finalmente, el subdominio [vendimia/ Weinlese] contiene los subdominios [maduración/ Reife], [recolección/ Ernte] y [transporte/ Transport].

Del mismo modo, el dominio [producción/ Herstellung] contiene dos grandes subdominios: [vinificación/Weinherstellung] y [tipos de vinificación/ Weinherstellungssorte]. Dentro del primero, encontramos los subdominios [recepción/ Empfangen], [sulfitado/ Schwefelung], [estrujado/ Auspressen], [despalillado/ Abbeeren], [fermentación/ Gärung] y [prensado/Keltern]. Dentro del segundo encontramos los subdominios [vinificación de blanco/Weißweinherstellung], [vinificación de rosado/ Roseweinherstellung], [vinificación de tinto/ Rotweinherstellung], [vino espumoso/Schaumwein], [vino de hielo/ Eiswein], y [tipos de vino/ Weinsorte] —dentro del cual, a su vez, distinguimos los subdominios [vino tinto/ Rotwein], [vino blanco/Weißwein], [vino rosado/ Rosewein], [envejecimiento/ Reifung], [cava/ spanischer Sekt] y [vinos generosos/ Dessertwein]-.

\section{Ejemplo de clasificación y búsqueda de equivalencies: el subdominio [patología vitícola/ Rebkrankheiten]}

Un minucioso trabajo de documentación, así como la elaboración de léxicos propios, ayudará al traductor a poder determinar las equivalencies posibles en textos vitivinícolas de carácter especializado. El Proyecto Weinapp propone una sencilla ficha para poder extraer términos de textos reales, y, a su vez conseguir la clasificación semántica y conceptual necesaria para conformar un lexicon multilingüe. En el caso de las lenguas de trabajo que aquí nos ocupan, esto es, alemán-español, proponemos la siguiente ficha:

Tabla 1. Ficha terminológica

\begin{tabular}{|c|c|}
\hline TÉRMINO ORIGINAL (ES) & \\
\hline Tipo de/ Parte de & Patología vitícola \\
\hline Pertenece al subdominio & \\
\hline Fase & \\
\hline Función / Efecto & \\
\hline Equivalencia & Término meta (DE) \\
\hline
\end{tabular}

Así, la ficha correspondiente al término "oídio" sería la siguiente:

Tabla 2. Ficha terminológica de "oídio"

\begin{tabular}{|l|l|}
\hline OÍDIO & \multicolumn{1}{|l}{} \\
\hline Tipo de/ Parte de & [Patología vitícola] \\
\hline Pertenece al subdominio & [Hongos] \\
\hline Fase & $\begin{array}{l}\text { Contamiento. Compactación de racimo de hónaca de bayas y } \\
\text { racimos, con aspecto de ceniza. }\end{array}$ \\
\hline Función / Efecto & Oidium, echte Mehltau, Äscherisch \\
\hline Equivalencia(s) &
\end{tabular}


Si tomamos como ejemplo el subdominio [fenología/ Phänologie] siguiendo el modelo de ficha propuesto, obtenemos las siguientes equivalencias léxicas:

Tabla 3. Lexicología contrastiva ES-DE. [Fenología/ Phänologie]

\begin{tabular}{|l|l|}
\hline Término en lengua original (ES) & Término en lengua meta (DE) \\
\hline [fenología] & [Phänologie] \\
\hline parada invernal & Winterruhe \\
\hline hinchado de yemas & Knospenschwellen \\
\hline desborre & Wollstadium \\
\hline botones, yemas & Knospen \\
\hline zarcillos & Ranken \\
\hline aclarado, deshojado & Blätter entfalten \\
\hline inflorescencias visibles & sichtbare Gescheine \\
\hline inicio de la floración & Blutbeginn \\
\hline floración plena & Vollblüte \\
\hline botones frutales & Fruchtknoten \\
\hline estambres & Staubblätter \\
\hline desarrollo del fruto & Fruchtenwicklung \\
\hline baya & Beere \\
\hline raspajo & Traubenkamm \\
\hline inicio de la maduración & Reifebeginn \\
\hline coloración, envero & Farbungschlag \\
\hline cosecha & Ernte \\
\hline
\end{tabular}

Lo mismo ocurre con los subdominios [sulfitado/Schwefelung] y [fermentación/ Gärung]:

Tabla 4. Lexicología contrastive ES-DE [Sulfitado/ Schwefelung]

\begin{tabular}{|l|l|}
\hline Término en lengua original (ES) & Término en lengua meta (DE) \\
\hline [sulfitado] & [Schwefelung] \\
\hline & schweflige Säure \\
\hline & Schwefeldioxid \\
\hline & Kaliumdisulfit, Kaliumpyrosulfit \\
\hline & enzymatische Bräunung \\
\hline & Essigsäurebakterien \\
\hline bacterias del ácido láctico & Milchsäurebakterien \\
\hline & Überschwefelung \\
\hline
\end{tabular}

Tabla 5. Lexicología contrastive ES-DE [Fermentación/ Gärung]

\begin{tabular}{|l|l|}
\hline Término en lengua original (ES) & Término en lengua meta (DE) \\
\hline [fermentación] & [Gärung] \\
\hline barriles, barricas, botas & Fässer \\
\hline tanke metálico & Metaltank \\
\hline levaduras [del azúcar] exógenas & exogene Zuckerhefen \\
\hline fermentación principal & Hauptgärung \\
\hline
\end{tabular}




\begin{tabular}{|l|l|}
\hline realizar el proceso de fermentación & durchgären \\
\hline $\begin{array}{l}\text { fermentación con control de } \\
\text { temperature }\end{array}$ & temperaturkontrollierte Gärung \\
\hline fermentar & vergären \\
\hline sustancias aromáticas & Aromastoffe \\
\hline sustancias gustativas & Geschmackstoffe \\
\hline proceso de fermentación & Gärvorgang, Gärprozess \\
\hline concentración [alcohólica] en volume & Volumenprozent \\
\hline interrupción de la fermentación & Gärunterbrechung \\
\hline trockener Wein & vino seco \\
\hline halbtrockener Wein & vino semi-seco \\
\hline lieblicher Wein & vino amable \\
\hline süßer Wein & vino dulce \\
\hline malolaktische Gärung & fermentación maloláctica \\
\hline ácido málico & Apfelsäure \\
\hline ácido láctico & Milchsärue \\
\hline
\end{tabular}

Este trabajo previo de búsqueda de términos y sus respectivos equivalentes en el par de lenguas de trabajo permitirá al traductor llevar a cabo con éxito su labor, y así poder enfrentarse a textos como los que ofrecemos a continuación a modo de ejemplos:

(1) [Oidium] Der Pilz überzieht Blätter, Beeren und Triebspitzen mit einem grauem Schimmel. Besonders in trockenen Jahren und bei empfindlichen Rebsorten können starke Beerenschädigungen eintreten. Die Beeren verdorren. Schon ein leichter Befall der Berren kann eine geruchliche Beeinträchtigung des Weines (Muffton) herbeiführen. Bekämpft wird diese Krankheit entweder mit Schwefel oder speziellen Fungiziden. ${ }^{2}$

(2) Die Gärung läuft in abgedichteten Fässern oder Metalltanks ab, welche mit Gärverschlüssen versehen sind. Durch hinzufügen spezieller Hefe wird der Gärvorgang in Gang gebracht. Die Hauptgärung dauert 6-8 Tage. In dieser Zeit wird der im Most enthaltene Zucker zu Alkohol umgesetzt. Während der Gärung kann sich die Flüssigkeit auf bis zu $30{ }^{\circ} \mathrm{C}$ erwärmen. (...) Nach dem Gärvorgang erreichen die meisten Weine zwischen 8 und 13 Volumen-Prozent Alkohol. Außer Alkohol entstehen noch ungefähr 400 andere Verbindungen, die Einfluss auf den Geruch und den Geschmack des Weines haben. Wenn der Most komplett durchgegoren wird, erhält man «trockenen» Wein. Wird die Gärung vorzeitig unterbrochen (Gärunterbrechung), erhält man je nach Menge des unvergorenen Restzuckers «halbtrockenen» («lieblichen») oder süßen Wein, ${ }^{3}$

\section{Conclusiones}

Lo expuesto en las páginas precedentes nos lleva a establecer las siguientes conclusiones:

1. La traducción de textos vitícolas es una traducción especializada, como muestran buena parte de los términos y textos que hemos ofrecido a lo largo de este estudio. Dado que se trata de una traducción especializada, el traductor habrá de conocer el léxico especializado que contienen los textos.

\footnotetext{
${ }^{2}$ Fuente: http://www.gastronews.wien/2014/08/2138/. [Fecha de consulta: 16 de mayo de 2017].

${ }^{3}$ Fuente: http://www.simmendinger.ch/index.php?id=13. [Fecha de consulta: 16 de mayo de 2017].
} 
2. Por ello, es imprescindible disponer de recursos apropiados para poder proceder a la traducción de dichos textos. En este sentido, Weinapp pretende ser una base de datos terminológica multilingüe que permita al usuario encontrar las equivalencias adecuadas, entre otros, en el par de lenguas alemán-español.

3. Finalmente, el conocimiento de la estructura gramatical y morfosintáctica de las lenguas origen (alemán) y meta (española) posibilitará al traductor la comprensión adecuada de los conceptos, y, por ende, la búsqueda de equivalencias adecuadas.

\section{References}

Bajo Santiago, F. (2001). El léxico científico-técnico del vino en el DRAE. En M. T. Bargalló et. al. (Eds.), Las lenguas de especialidad y su didáctica. Actas del Simposo Hispano-Austríaco (pp. 69-80). Tarragona: Universitat Rovira i Virgili. Barahonda Mijancos, L. (2010). La traducción del spot publicitario del vino. En M. Ibáñez (Coord.), Vino, lengua y traducción (pp. 367-376). Valladolid: Universidad de Valladolid, Secretariado de Publicaciones e Intercambio Científico.

Eggelte; B. \& Sánchez Heinz, R. (2010). Textos en la red en español y alemán. Un proyecto contrastivo hispanoalemán. Correos electrónicos de pymes del sector vitivinícola y alimentario. En M. T. Ramos (Coord.), El vino y su publicidad: de la economía a la lingüística (p. 11). Valladolid: Universidad de Valladolid, Secretriado de Publicaciones e Intercambio Científico.

Iglesias Iglesias, N. M. (2010). Estudio contrastivo de las expresiones idiomáticas en torno a vino (español) y Wein (alemán) En M. T. Ramos (Coord.), El vino y su publicidad: de la economía a la lingüística (p. 13). Valladolid: Universidad de Valladolid, Secretriado de Publicaciones e Intercambio Científico.

Ibánez Rodríguez, M. \& Sánchez Nieto, M. T. (2006). (Coords.). El lenguaje de la vid y el vino y su traducción. Valladolid: Servicio de publicaciones e Intercambio Editorial de la Universidad.

Schumann, F. (1998). Weinbau-Lexikon. Neustadt an der Weinstraße: Meiniger Verlag. 